\title{
Non-universal suffrage: measuring electoral inclusion in contemporary democracies
}

\author{
Samuel D. Schmid ${ }^{1}$. Lorenzo Piccoli ${ }^{2}$ Jean-Thomas Arrighi ${ }^{2}$ \\ Published online: 14 February 2019 \\ (c) The Author(s) 2019
}

\begin{abstract}
The electoral franchise has become more universal as restrictions based on criteria such as sex or property have been lifted throughout the process of democratisation. Yet, a broad range of exclusions has persisted to this date, making the suffrage nonuniversal, even in established democracies. In this article, we present ELECLAW, a new set of indicators that captures the subtle and variegated legal landscape of persisting electoral rights restrictions. We measure the inclusiveness of the right to vote and the right to stand as candidate across four levels and three types of elections for three categories of voters: citizen residents, non-citizen residents, and non-resident citizens. ELECLAW currently covers fifty-one democracies in three different continents (the Americas, Europe, and Oceania) depicting the legal situation in 2015. The article introduces the methodology used for building the indicators so as to make it transparent to the broader research community. To this aim, it successively unpacks the conceptualisation underlying the indicators, explains the measurement by providing specific examples, and discusses the merits of a differentiated and contextdriven method of aggregation.
\end{abstract}

Keywords Voting rights · Candidacy rights · Citizenship · Elections · Democracy measurement $\cdot$ Index building

The online version of this article is available Open Access

Electronic supplementary material The online version of this article (https://doi.org/10.1057/s4130 4-019-00202-8) contains supplementary material, which is available to authorized users.

Samuel D. Schmid

samuel.schmid@eui.eu

1 European University Institute, Badia Fiesolana, Via dei Roccettini 9, 50014 San Domenico di Fiesole, FI, Italy

2 Swiss Forum for Migration and Population Studies, University of Neuchâtel, Rue Abram-Louis-Breguet 2, 2000 Neuchâtel, Switzerland 


\section{Introduction}

Who can vote? And who can stand as a candidate? The answers to these questions lie at the heart of democracy. Only those included in the demos can elect representatives, and who can become a representative hinges upon who can run for office in the first place.

In the past two centuries, the suffrage has become more universal, as restrictions based on property, literacy, religion, sex or race have been gradually lifted through a global diffusion of the democratic ideal. The process has not been an irresistible march towards a fully universal endpoint, but a fiercely contested struggle punctuated by episodes of retrenchment, and expansion that were simultaneously fought in local, regional, national, and supranational arenas (Rokkan 1999: 247-257). Today, the battle of the suffrage has not come to an end. Instead, it is being fought along different frontlines. While significantly less contentious than in the past and affecting smaller segments of the population, it reveals the same tension between the democratic promise of equality and a reality of pervasive differentiation. The exclusion of prisoners or persons with a mental disability, for instance, remains a divisive issue in most contemporary democracies. Another particularly widespread and controversial form of disenfranchisement stems from international migration, as a result of which non-naturalised immigrants are often excluded from elections held in their country of residence and, to a lesser degree, in their country of citizenship (Earnest 2015; Pedroza 2015; Spiro 2006; Arrighi and Bauböck 2017). In democratically governed states, regions, and cities, these infringements to the sacrosanct principle of universal suffrage have sparked debates about the very nature of the political community and the essential qualities of citizenship, resulting in frequent changes in the electoral law. Ultimately, a broad range of more or less severe restrictions has persisted to this date, making suffrage non-universal, even in established democracies.

In this article, we present ELECLAW, a new set of indicators designed to measure the inclusiveness of the right to vote (VOTLAW) and the right to stand as candidate (CANLAW) across four levels (supranational, national, regional, and local) and three types of elections (executive, legislature, and referendum) for three categories of voters (citizen residents, non-citizen residents, and non-resident citizens) (GLOBALCIT 2019). The dataset currently covers 371 kinds of elections in fiftyone democracies in three different continents (the Americas, Europe, and Oceania), depicting the legal situation in 2015, and, for the subset of elections held within the EU-28, in both 2013 and $2015 .{ }^{1}$ In the future, we plan to continue updating the data and expanding the coverage to other world regions as well as back in time.

ELECLAW captures the subtle and variegated legal reality of both voting rights and candidacy rights across established democracies in a comprehensive and

\footnotetext{
1 The following countries are included: Argentina, Australia, Austria, Belgium, Bolivia, Brazil, Bulgaria, Canada, Chile, Colombia, Costa Rica, Croatia, Cyprus, Czech Republic, Denmark, Ecuador, El Salvador, Estonia, Finland, France, Germany, Greece, Guatemala, Honduras, Hungary, Ireland, Italy, Latvia, Lithuania, Luxembourg, Malta, Mexico, the Netherlands, New Zealand, Nicaragua, Panama, Paraguay, Peru, Poland, Portugal, Romania, Slovakia, Slovenia, Spain, Suriname, Sweden, Switzerland, UK, USA, Uruguay, Venezuela.
} 
fine-grained way. It zooms in on the very edge of the new frontiers of the demos, as it is expanding and contracting beyond membership and territory, but also (re-)defining internal boundaries within the resident citizenry. Identifying a broad range of variation across groups of potential voters, levels of government, and types of elections, it widens the horizon of the scholarship on democracy measurement by focusing on the democratic quality of electoral inclusiveness (see Blatter et al. 2015a).

The main purpose of this article is to introduce the methodology used for building the index to make it transparent to the broader research community. After providing a justification for the need of ELECLAW in the next section, the presentation follows the silver thread that has become common practice in index building (Munck and Verkuilen 2002). We successively unpack the conceptualisation underlying the indicators, explain the measurement by providing specific examples, and discuss the merits of a differentiated method of aggregation. Our discussion primarily aims to highlight the most significant methodological challenges we encountered when building the index. As such, it does not describe all aspects of the indicators, nor present the comparative empirical findings. For a comprehensive description, interested readers and users can consult our explanatory note (Schmid et al. 2019). A glimpse at our comparative results for each of our category of voters is available in the online supplementary file, as well as on our interactive visualisation web page.

ELECLAW builds upon the data made available by the Global Citizenship Observatory (GLOBALCIT). ${ }^{2}$ Like many existing indices, users may freely download the data disaggregated to the lowest level and in full knowledge of how it was processed. However, note that the resources made available by GLOBALCIT go one step further: for each score, users may consult the corresponding legal provision summarised in our Conditions for Electoral Rights Database, access the original full text legislation in our National Electoral Law Database, and place the legislation in the broader political and historical context in which it came about thanks to our Country Reports on Access to Electoral Rights. ${ }^{3}$

\section{Towards the inclusion of inclusiveness}

The ubiquity of the new battles of the suffrage recently caught the eye of normative theorists. It revived a long-standing puzzle on the "problem of inclusion" (Dahl 1989: 119-133) that earlier generations of philosophers took issue with, from John

\footnotetext{
${ }^{2}$ GLOBALCIT (www.globalcit.eu) is a research observatory within the Robert Schuman Centre of Advanced Studies at the European University Institute in Florence (Italy). It provides fact-based and nonpartisan analysis of citizenship laws and policies around the globe.

3 All the data collected for building the indicators as well as the disaggregated dataset in csv or xls format can be freely accessed and downloaded on the Electoral Rights web page of GLOBALCIT at www. globalcit.eu/electoralrights. This includes the comparative database Conditions for Electoral Rights (CER 2017; see Piccoli et al. 2017), the Country Reports Series on Access to Electoral Rights, and the ELECLAW indicators interactive visualisation page.
} 
Stuart Mill to Joseph Schumpeter (see, inter alia, Arrhenius 2018; Bauböck 2015, 2017; Beckman 2009; Goodin 2007; López-Guerra 2014). But while the debate struck back with a vengeance in political theory, it has been largely left at the margins of empirical scholarship on democracy measurement. In fact, there is a gap between the conceptualisation of inclusion as a necessary condition for democracy on the one hand and the actual content of existing democracy measures on the other (Blatter et al. 2015a). Although Dahl's concept of "polyarchy" (1971) operated with two dimensions of contestation and inclusiveness, over the next decades the strong empirical focus of democracy measurement and research on contestation has turned into "the common assumption that most existing indicators of democracy measure the same single dimension" (Coppedge et al. 2008).

Based on a large array of existing indicators, Michael Coppedge and colleagues (ibid.) have demonstrated that this assumption is wrong. Instead, their compilation of indicators reveals two empirical dimensions, which can be understood as contestation and inclusiveness. However, the inclusiveness indicators focus on fundamental aspects such as the existence of adult suffrage for both genders in the group of resident citizens, or refer to de facto participation rates (Vanhanen 1990) rather than electoral laws as such. Hence, existing indicators cannot detect legal differences along the new frontiers of suffrage. Instead, they are tools to trace democratisation processes.

The more recent wave of democracy measurement has two streams. The first flows towards the quality of democracy, while the second drifts towards the varieties of democracy (Blatter et al. 2015a). For instance, the Democracy Barometer aims to capture differences between established democracies and their democratic quality (Bühlmann et al. 2012). It features measures of voting and candidacy rights, but they are crude in design (summative scales with dichotomous indicators; see Merkel et al., 2016: 44-45, 51-52) and conflate different target groups (including non-citizen residents and non-resident citizens), while only considering national legislative elections. In addition, the indicators are of marginal importance for the aggregate score of democratic quality, which is based on a total of one hundred indicators (for a more detailed discussion see Blatter et al. 2015a: 21-22).

The core idea of the Varieties of Democracy project is that while democracy comes in different shades, both normatively and empirically, at the heart of any conception there are free and fair (or contested and inclusive) elections (Coppedge et al. 2011). However, the core suffrage indices measure the de facto inclusion of adult citizen residents in national elections only (Coppedge et al. 2018; for a more detailed discussion see Blatter et al. 2015a: 22-24). Moreover, the data indicate that, at least in the new millennium, all established democracies have a perfect score on these indicators (ibid.). The same problem arises in the study by Paxton et al. (2003), which is focused solely on suffrage: while various restrictions such as those for criminal convicts, the mentally disabled, non-citizen residents, and nonresident citizens are considered, the resulting measure shows very little variation across established democracies. Besides, again, only national legislative elections are considered.

It is at this frontier of democracy measurement that ELECLAW comes in. It can be used to comprehensively and systematically compare the legal shape of 
the demos regarding multiple groups of voters, multiple levels of government, and multiple types of elections. We hope that in doing so we can help pave the way for research analysing the degrees, causes, and consequences of electoral inclusiveness in the context of international migration and multilevel politics across established democracies in the twenty-first century.

\section{Conceptualisation}

In a representative democracy, individuals may participate in elections in two ways: by voting and by standing as candidates. In practice, the rules of access to candidacy are often different and comparatively more demanding than the former. For instance, the age requirement in Brazilian national legislative elections is only sixteen for voting but increases to thirty-one for standing as a candidate. Similarly, a growing number of countries that have extended the right to vote to foreign residents in local elections have been more reluctant to let them run for the post of city mayor or even municipal councillor (see supplementary file online). We thus disaggregate at the onset the concept of electoral rights into its two main components: the right to vote (VOTLAW) and the right to stand as candidate (CANLAW).

All supporters of democracy share the view that suffrage should in principle be universal. However, disagreements eventually appear as soon as one leaves the realm of abstraction for the messier field of real-world democracies. For instance, a cosmopolitan may see New Zealand, which grants the right to vote to foreigners in all types, and levels of elections after 1 year of legal residence, as more democratic than its Australian neighbour, which reserves that right to its own citizens. Conversely, a communitarian may see the New Zealand practice as less democratic because it unduly dilutes citizens' preferences and disrupts the fair representation of their interests in government with the ballots cast by persons who did not signal their belonging to the political community through naturalisation. But even though there is no consensus as to what constitutes the ideal demos, arguing that the New Zealand legislation is more inclusive than the Australian one regarding non-citizen residents is an empirical fact that leaves no room for disagreement. Our indicators thus measure the relative degree of electoral inclusiveness of both voting and candidacy rights, a concept that minimises the need for normative judgment ${ }^{4}$ and allows for systematic comparison across time and space without privileging one conception of democracy over another.

The concept of electoral inclusiveness has two dimensions. First, eligibility restrictions determine who has the right to vote or stand as a candidate based on explicit legal qualifications. Second, access restrictions determine how those eligible can exercise their right to vote in terms of registration procedures and voting methods. ${ }^{5}$ We do not consider access restrictions for candidacy rights, because our

\footnotetext{
${ }^{4}$ ELECLAW can still be adapted and used for normative analyses. An example of a normative application of ELECLAW is the Immigrant Inclusion Index (IMIX; Blatter et al. 2015b, 2017).

${ }^{5}$ Our analysis of access-related restrictions is limited to the most widespread and significant restrictions that we found in the electoral legislation. We acknowledge that there may be other forms of access restriction that we do not capture. One may argue, for instance, that the degree of electoral inclusiveness is lower in those countries where elections are held on weekdays, e.g. the USA and the UK. However, in, those countries where elections take place on a working day, voters usually are offered a range of alterna-
} 
focus is on electoral rights as an aspect of citizenship rather than as a procedure for selecting office-holders. We also leave aside electoral regulations whose inclusiveness cannot be measured across time and space because this is contingent upon contextual factors. This includes mandatory voting and issues of voter representation, that is, how individual votes are aggregated into seats in legislative elections. ${ }^{6}$ This qualitative information can easily be retrieved in our online database and country reports.

Our measurement is based on de jure regulations as specified in electoral laws. This includes both primary and core aspects of implementing legislation, namely access restrictions. We therefore strictly focus on policy outputs and do not consider policy outcomes such as the number of affected voters or turnout. In doing so, we follow Easton (1965: 351), who defines "outputs" broadly to include both the "binding decisions" and the "implementing actions". This analytical separation of outputs and outcomes enables causal analysis. As we make available disaggregated data, users can choose whether to narrow the notion of policy output to exclude implementation (see e.g. the approach of Helbling et al. 2017).

Democracy indices usually restrict the analysis to national legislative elections to highlight similarities and differences across states. By doing so, they obscure the fact that the rules of inclusion in the demos also vary within states, a phenomenon that can only be captured once one adopts a scale-sensitive view of contemporary democracies (Arrighi and Bauböck 2017). Theoretically, we identify three types of elections (executive, legislature, and referendum ${ }^{7}$ ) at four levels (supranational, ${ }^{8}$

\footnotetext{
Footnote 5 (continued)

tive and arguably convenient voting methods to cast a ballot on election day, chiefly postal voting. Since it overlaps with our "voting" methods' indicators, this aspect of the organisation of elections was not included.

${ }^{6}$ Issues of representation are particularly relevant in the case of non-resident citizens in legislative elections. In most countries, votes are either merged with those of the electorate in their domestic constituency of origin or assigned to a particular constituency (assimilated representation). In other instances, they may directly elect their own representatives in Parliament through reserved seats for the diaspora (special representation). The latter has been introduced in a number of countries including France, Croatia, Colombia, Portugal, Italy, and Tunisia. However, whether one mode of representation is more electorally inclusive than another because it increases the relative weight of the external electorate is an empirical question that is contingent upon contextual factors in a particular election (Collyer 2014; Arrighi and Hutcheson 2015).

7 Here, we understand "referendum" as a generic term for all democratic elections that consist in a general vote by the electorate on a single political question which has been referred to them for a direct decision. This includes both referendums that were triggered "from the top" by the executive or legislative branches of government and those that were triggered "from the bottom" through the collection of a minimum number of signatures among the electorate, usually referred to as popular initiatives.

${ }^{8}$ In our dataset, the supranational level includes elections to the European Parliament (28 member states), the Andean Parliament (Bolivia, Colombia, Ecuador, and Peru), the Central American Parliament (El Salvador, Guatemala, Honduras, Nicaragua, and Panama), and the Mercosur Parliament (Argentina, Brazil, Paraguay, Uruguay, and Venezuela). However, some countries in our sample, like the USA, Canada, Australia, or New Zealand, are not part of a supranational union endowed with a democratically elected Parliament.
} 
Table 1 Levels and types of elections

\begin{tabular}{lcclcr}
\hline & Supranational & National & Regional & Local & Total \\
\hline Executive & 0 & 32 & 16 & 35 & 83 \\
Legislature & 42 & 51 & 33 & 49 & 175 \\
Referendum & 0 & 47 & 27 & 39 & 113 \\
Total & 42 & 130 & 76 & 123 & 371 \\
\hline
\end{tabular}

The cells report the total number of elections based on the combination of types and levels in our sample of countries $(N=51)$

national, regional, and local ${ }^{9}$ ) that, once combined, lead to twelve potential kinds of elections periodically held in a single country. The table below shows these combinations as well as the number of countries in our current dataset where they do exist as of 2015 (Table 1).

Electoral inclusiveness not only varies across kinds of elections, but also across categories of potential voters and candidates. As mentioned in the introduction, some of the most significant franchise restrictions in today's democracies result from protracted international migration, which creates a mismatch between resident and citizen populations and leads to new forms of inclusion and exclusion. We thus distinguish between three categories of potential voters and candidates, which broadly correspond to sedentary, emigrant, and immigrant populations, respectively: resident citizens, who are citizens of a state in which an election is held and who are also permanent residents there; non-resident citizens, who reside outside of the territory of the state of which they hold citizenship and in which the election is held; and non-citizen residents, who are residents in a state where the election is held, and who are not citizens of that state. To be sure, our legal categories of non-citizen residents and non-resident citizens are different from the sociological distinction between immigrant and emigrant populations. A person may still be registered as a resident in a municipality while living elsewhere, and a non-resident citizen may never have lived in her country of citizenship (Dumbrava 2014). But legal reality is precisely what the ELECLAW indicators aim to measure, and the conceptual distinction between our three groups of persons allows us to capture a broad range of restrictions while avoiding coding redundancies.

Some of these restrictions were easy to identify. As far as resident citizens are concerned, electoral laws always specify a minimum age threshold, and qualifications

\footnotetext{
9 Not all countries hold regional and local elections. For instance, some countries do not have a regional tier of government (e.g. Malta, Cyprus, Luxembourg), while in others, regional representatives are not directly elected (e.g. Ireland). In countries like El Salvador and Honduras, the local legislature is not directly elected. In the European Union, all countries hold municipal elections, but the local executive is indirectly elected in a majority of member states.
} 
on mentally disabled citizens or those who committed a criminal offence are almost as frequent. However, other restrictions are less obvious and came to our knowledge throughout the data collection process. For example, the persistence of qualifications targeting members of the armed forces and the clergy in several Latin American countries was somewhat unexpected and encouraged us to add another eligibility restrictions based on professions. Overall, the restrictions covered in ELECLAW aim to capture the particular challenges that each group of potential participants faces for accessing the ballot or running as candidates. For example, restrictions based on nationality only apply to non-citizen residents (cf. Fig. 3) and are meant to distinguish between electoral laws that selectively enfranchise nationals of specific countries (e.g. local elections in Spain or Bolivia) and those that do not discriminate between foreigners but only require a minimum length of residence in the country (e.g. all elections in Chile or local elections in Denmark). They are qualitatively different from restrictions barring naturalised citizens (e.g. all elections in Panama), dual citizens (e.g. national legislative elections in Bulgaria), or citizens born abroad (e.g. presidential elections in the USA) from standing as candidate, which are also covered under our resident citizen category (cf. Figs. 1, 2, and 3).

\section{Measurement}

ELECLAW is based on the resources of GLOBALCIT. The original material was gathered by country experts, who were asked to collect the electoral legislation in force in their country, to summarise the relevant legal provisions in a questionnaire, and to write a narrative report on access to electoral rights. However, the resulting databases were compiled centrally by our team. The coding of ELECLAW was also centralised: one specially assigned collaborator took the lead, while two additional collaborators checked the coding and discussed entries where there were uncertainties or disagreements. In addition, most collaborators were involved in crafting the coding rules, which helped ensure that they were strictly adhered to or modified on the go to capture unanticipated and relevant real-world complexities. This centralisation strategy, together with our focus on de jure regulations, minimises the interpretative bias which arises when the task of evaluating the data is delegated to national experts who are often less acquainted with the broader comparative picture. ${ }^{10}$

ELECLAW measures the degree of electoral inclusion of a given legal provision using a scale ranging from a minimum of 0 to a maximum of 1 . In case of eligibility restrictions, this usually translates into theoretical minima and maxima of 0 for "generally disenfranchised" and 1 for "generally enfranchised". For all other indicators, the determination of the minima and maxima is empirically determined, though these minima and maxima often reflect what is theoretically possible. For instance,

\footnotetext{
10 While our coding method ensures a high degree of accuracy, it is not fully immune to residual errors or inconsistencies. We seek to correct false information in subsequent versions of ELECLAW. To this end, we are always open to user feedback.
} 


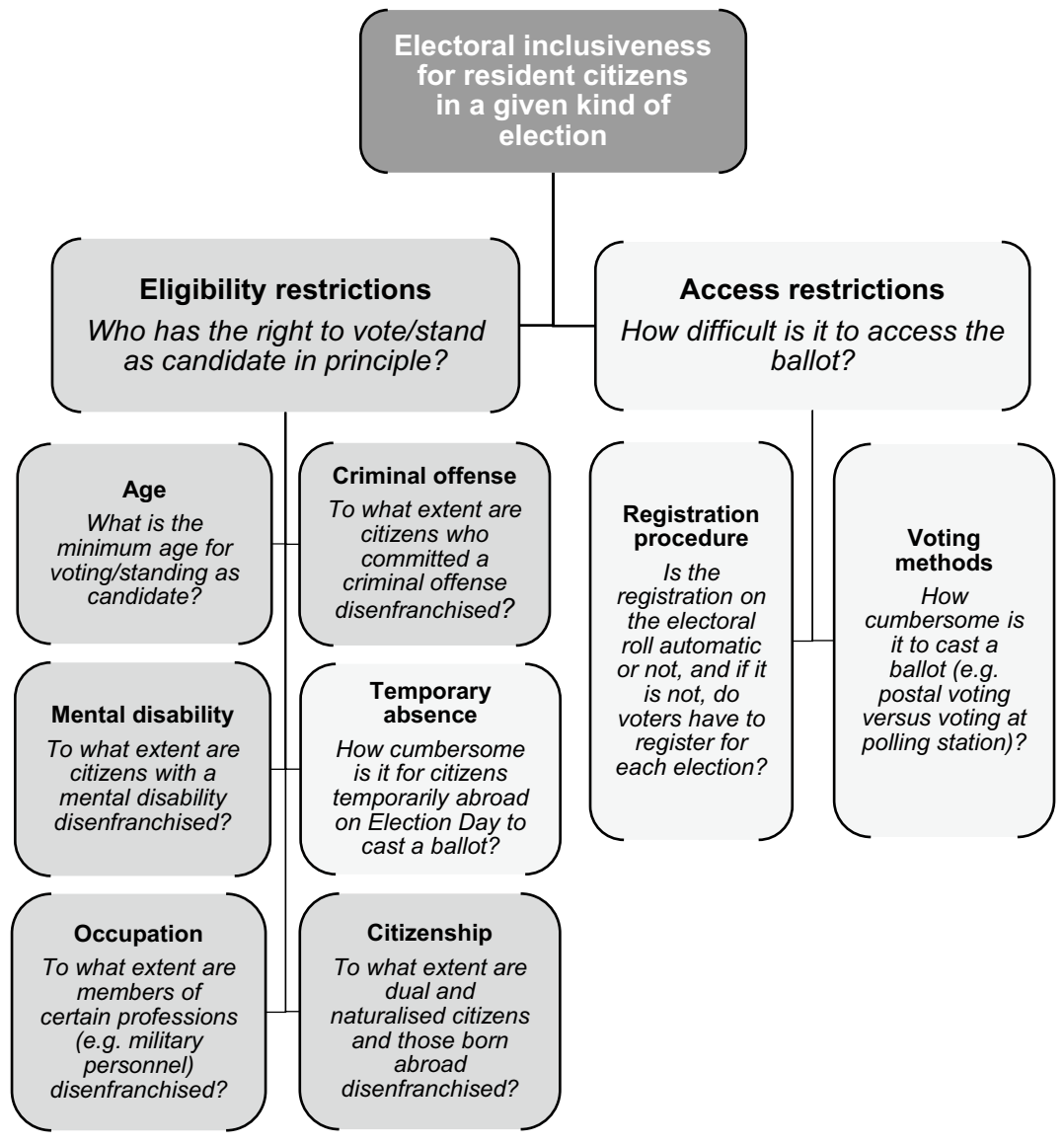

Legend

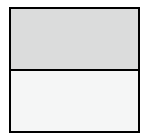

Applies to voting rights (VOTLAW) and candidacy rights (CANLAW)

Applies to voting rights (VOTLAW) only

Fig. 1 Electoral inclusiveness for resident citizens in a given kind of election

automatic registration is arguably the least cumbersome form of accessing the ballot and thus coded 1.

ELECLAW scales are ordinal. The number of points between the 0 and 1 endpoints varies depending on the relevant qualitative distinctions that can be drawn based on the data. The $0-1$ scale is split up into equal intervals between the points to yield an intuitive ordinal construct. Distances between points on different scales therefore may vary and are not strictly comparable across individual indicators. Still, this method allows for plausible aggregation as long as the underlying measurement level is adequately considered in subsequent analyses. 


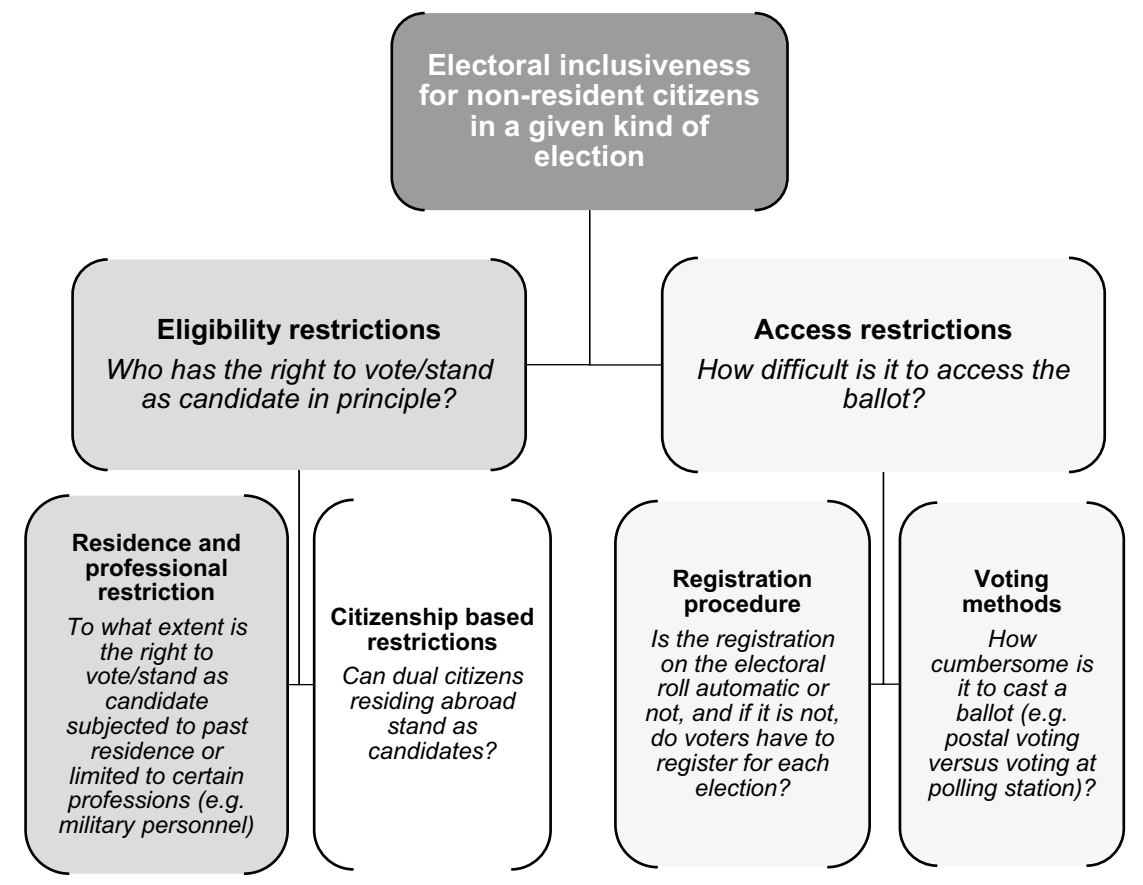

Legend

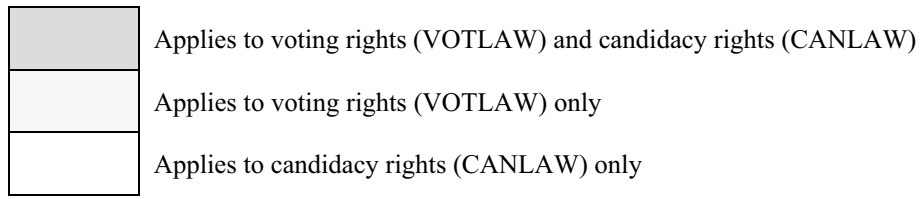

Fig. 2 Electoral inclusiveness for non-resident citizens in a given kind of election

We illustrate the logic of measurement in ELECLAW by discussing three examples. The first is voting rights restrictions for resident citizens based on mental disability (see Table 2). It was obvious from the start of our coding process that no disenfranchisement would be the most inclusive regulation, while a blanket disenfranchisement of all legally incapacitated persons would be the most restrictive. In order to construct our mid-point scales, our attention was drawn to an influential 2010 judgement of the European Court of Human Rights that found that an absolute ban on legally incapacitated persons violated the right to free elections enshrined in the Convention. ${ }^{11}$ A key distinction arises between those electoral regulations applying to a general category of persons and those providing for a separate assessment of the functional abilities that are relevant for the

11 Alajos Kiss versus Hungary, judgement of the European Court of Human Rights, 20 August 2010.

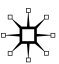




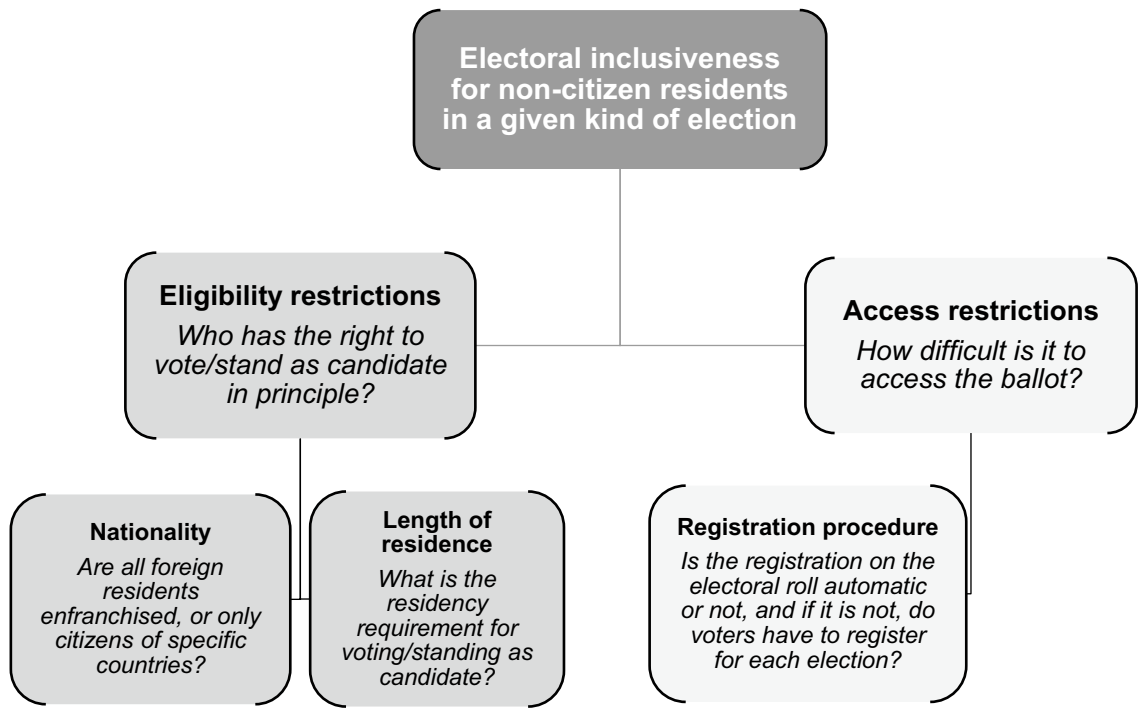

Legend

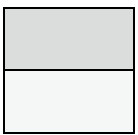

Applies to voting rights (VOTLAW) and candidacy rights (CANLAW)

Applies to voting rights (VOTLAW) only

Fig. 3 Electoral inclusiveness for non-citizen residents in a given kind of election

Table 2 Voting rights restrictions for resident citizens based on mental disability

Indicator name: VRCMEN

No disenfranchisement

Separate judicial decision on disenfranchisement of hospitalised persons OR legally incapacitated persons

Automatic disenfranchisement for specific categories of hospitalised persons OR legally incapacitated person

Automatic disenfranchisement of all hospitalised persons OR legally incapacitated person

act of voting (Raad et al. 2009: 624; see also Beckman 2014). We therefore drew on this aspect to construct an empirically informed four-point scale that measures how severe the exclusion is in a fine-grained way (cf. Table 2). It captures whether the disenfranchisement must be subjected to a proportionality test, and if it is not, whether it applies indiscriminately to all persons found to be fully legally incapacitated or hospitalised in a mental institution or to specific categories only. Accordingly, France, where, since 2007, a judge must rule on the retention or abolition of the right to vote of a protected person when ordering or renewing a measure of 
Table 3 Voting rights restrictions for non-resident citizens based on voting methods

\begin{tabular}{ll}
\hline Indicator name: VNRMET & \\
\hline Electronic voting & 1 \\
Proxy OR postal voting & 0.75 \\
Voting at embassy or consulate OR other polling station & 0.5 \\
$\quad$ abroad & \\
In-country voting, travel subsidised & 0.25 \\
In-country voting only, non-subsidised & 0
\end{tabular}

curatorship, was coded 0.67. By contrast, countries that disenfranchise all persons who were found legally incapacitated by a court decision, such as Argentina, Belgium, Poland, or Portugal, were coded 0.33.

The second example concerns voting rights for non-resident citizens. This is to illustrate the importance of considering not only eligibility, but also access. Obviously, these restrictions are especially relevant for non-resident citizens: any attempt to measure their electoral inclusion without considering this dimension would miss a crucial institutional aspect, which is in fact often used by governments to constrain the influence of the diaspora (Turcu 2018; Arrighi and Lafleur 2017). Greece is a case in point. Although the right to vote from abroad is constitutionally enshrined, it has never been implemented, thus effectively disenfranchising the Greek diaspora unless voters travel back to the country on Election Day. This aspect is captured in our five-point eligibility indicator, which attributes a score of 0.25 to those elections where the enfranchisement of non-resident citizens exists in principle but was not implemented, and our voting method indicator, where the combination of in-country voting and non-subsidised travel corresponds to the most exclusive category and is thus coded 0 (cf. Table 3 ).

Spain provides a more subtle example. In 2011, the introduction of the "voto rogado", whereby Spanish citizens abroad must activate their right to vote through a cumbersome procedure, considerably decreased turnout among the external electorate in subsequent elections (Merino 2015). Again, this administrative hurdle is accounted for in our coding. On the one hand, in the absence of past-residence or professional restrictions on the right to vote from abroad, Spain was given the maximum score 1 on our eligibility indicator (i.e. generally enfranchised). On the other hand, the combination of an active registration procedure with frequent renewal and postal voting was translated into a lower score in our access indicator.

More generally, we treat the electronic or online voting method as the most inclusive. One could argue that making available only this method excludes all those who are not digital natives. However, as there is no case we are aware of that allows for electronic voting without also supplying another method in parallel, this categorisation is viable. We therefore only code the most inclusive provision in case there are multiple options. The result is a four-point scale that captures how cumbersome the voting method is (see Table 3). 
The third example is that of voting rights for non-citizen residents. Here, we were confronted with the differential treatment of various groups. The first distinction is that of EU Second Country Nationals (SCN) and Third Country Nationals (TCN) across EU member states. We developed separate indicators to measure their inclusion. The indicator for TCN also serves as a general indicator for non-citizen residents. Thus, when comparing EU states with non-EU states, users can choose to either use only the TCN indicators or the aggregated indicator that takes into account that all EU states must grant voting rights to EU citizens in local legislative elections.

Our strategy for dealing with potential complexities is simple. We use the average score in case of multiple codes. For instance, in Nordic countries, Nordic non-EU citizens (from Iceland and Norway) have a lower residence requirement for local voting rights than other TCN. The score for residence-based eligibility restrictions for TCNs is thus the average of the score for Nordic TCN and all other TCN. We can also accommodate more complex cases such as local legislative elections in Portugal, where Brazilians, Cape-Verdean, and citizens of countries with reciprocity agreements have different residence conditions. This highlights the flexibility and fine-grained nature of ELECLAW.

\section{Aggregation}

Our aggregation strategy is differentiated, according to specific aims and contexts. First, we do not combine different groups of potential voters and/or candidates into an aggregate score; these groups are kept disaggregated. Second, we leave different levels of elections unaggregated, but argue that they can be aggregated depending on the research question. Finally, we do aggregate the indicators into composite scores for single elections as well as for levels of election.

We keep different categories of voters and candidates disaggregated because they concern distinct empirical dimensions that can no longer be recognised as such if they are buried under the gravel of an aggregate measure. For instance, if we want to compare countries regarding the expansion of the demos beyond the resident citizenry, aggregating the score for non-citizen voters and the score for non-resident citizens can obscure relevant differences. Take the cases of Ireland and Mexico. Ireland has a high level of inclusion of non-citizen residents of all nationalities in local elections (score 0.92 ) but enfranchises only some specific categories of nonresident citizens - i.e. diplomatic personnel and their spouses-in national elections (score 0.15 ). Mexico, by contrast, does not enfranchise any non-citizen residents on the local level (score 0), while having a high level of inclusion of non-resident citizens on the national level (score 0.93). The resulting problem is obvious: a simple average would make us think that both countries are moderately inclusive $(0.535$ for Ireland vs. 0.465 for Mexico). To be sure, it would not be wrong to state that, overall, Ireland is more inclusive than Mexico. But since we do not know who exactly is included to what degree, such a statement is potentially misleading. Indeed, the example shows that aggregating across groups of voters makes us miss a crucial qualitative difference: Ireland has a post-national demos-where residence is both 
a necessary and sufficient condition for voting, at least on the local level-whereas Mexico has a de-territorialised one-granting the right to vote to all persons holding Mexican citizenship, but only such persons. Therefore, although users can decide freely how to use ELECLAW data, we think various categories of voters or candidates should be kept disaggregated.

Different levels of elections as well as voting and candidacy rights also form empirically distinct dimensions, variation on which would be obscured if they were fused together in a single measure. Therefore, we do not aggregate these dimensions. However, in contrast to the conflation of groups of voters, they can be aggregated if researchers are interested in composite country and/or group-level scores of electoral inclusiveness. However, since collapsing multiple dimensions into one leads to a loss of information, we caution users of ELECLAW to consider very carefully what aggregation and weighting scheme to apply.

For single elections, we do aggregate eligibility and access scores. At first glance, the choice of an aggregation procedure seems straightforward. We could just attach a higher weight to eligibility than to access-since eligibility is arguably more important than access - and then calculate a weighted arithmetic mean, but it is not that simple. Averaging implies that high access scores could compensate low eligibility scores and this is logically inconsistent. More accessible ballots do not amount to more ballots; the number of eligible voters is not increased by making voting less difficult. This number can only be increased by increasing eligibility itselfor it can be reduced by introducing further eligibility restrictions alongside access restrictions.

Consider the example of non-citizen suffrage in national legislative elections in Portugal, where Brazilians are enfranchised and registered automatically after 3 years of residence. The 0.33 score for enfranchising one nationality can be modified by a deduction for the residence requirement (score of 0.75 on the residence indicator; transformed into a 0.05 deduction), but it is left untouched by the registration, which is automatic (score of 1 on the registration indicator; transformed into a 0 deduction). This yields a composite score of 0.28 for Portugal. By contrast, any averaging strategy using the original scores would lead to a score higher than 0.33 , which would suggest a higher level of eligibility than the one indicated by the underlying scale capturing basic eligibility in terms of nationality. Such a strategy might still lead to intuitive aggregate scores, but it would do so at the expense of rigorous "concept-measure consistency" (Goertz 2006: Chapter 4).

We also aggregate single elections into levels of elections. However, we do not weigh specific provisions by the relative significance of the type of election or the relative power of different legislative chambers. We acknowledge that context sensitivity and cross-national equivalence are important goals for valid concept formation and measurement. However, by isolating them from their broader political context we can avoid conflating our measures with variables that could be either a cause or consequence of the indicators. This is the reason why we always apply the arithmetic mean with equal weights to yield the aggregate score when we encounter significant contextual variations, such as the relative power of legislatures in different political systems or the frequency of actual referenda. 
As an alternative to aggregating election types and levels into a single countrywide score, ELECLAW also allows for shifting the unit of analysis to the elections themselves. The levels and types of election can then be used as independent variables forming parts of explanations for the degree of electoral inclusiveness in these elections (Arrighi and Bauböck 2017). For instance, the level of election is arguably important to explain the degree of non-citizen enfranchisement: local elections are far more inclusive than national ones (ibid.). Regarding non-resident voting rights, it could be hypothesised that not only the level of election but also the type of election is important. As we discuss in annex II, for example, the extraterritorial franchise in Latin America is mostly present in national executive elections, but much less frequent in parliamentary ones (see supplementary file online). In a similar vein, the candidacy age of citizen residents is on average much higher for national elections than it is for local and regional ones; in Bulgaria, Lithuania, and Slovenia, candidates in national presidential elections must be at least 40 years of age, while 18-year-old candidates can run for local and regional executives. These examples point to the relevance of variations in the political systems in which these elections are held. Indeed, from that perspective we deal with a multilevel data structure-371 elections nested within fifty-one countries - which provides another analytical strategy to grapple with the scale sensitivity that is inherent to ELECLAW.

\section{Conclusion}

Existing democracy indices mainly track the increasing electoral inclusiveness in processes of democratisation regarding basic criteria such as property- or genderbased restrictions and are often limited to the resident citizenry, as well as to national legislative elections. However, contemporary democratic polities continue to both expand and contract the franchise regarding various potential voters and candidates in multiple types of elections on multiple levels of government. ELECLAW provides a tool to compare the persisting voting rights and candidacy rights restrictions of resident citizens, non-resident citizens, and non-citizen residents for a total of 371 periodically held elections across fifty-one established democracies on three continents in 2015. In the future, we will update ELECLAW to account for the latest legislative changes in the countries already included in our sample, and we will expand our temporal and geographic coverage to earlier time periods and other regions. To this end, GLOBALCIT is open to collaboration with other research institutions.

ELECLAW can help to answer a variety of important questions across different literatures. First, relating to the literature on democracy measurement, ELECLAW can be analysed independently as a measure of electoral inclusiveness across established democracies, or be built into existing democracy measurement tools to better capture the fundamental dimension of inclusion. However, we would caution against conflating various dimensions in highly aggregated measures. Second, one could also analyse to what extent the general level, quality, or type of democracy is associated with voting right extensions for various groups of voters. Third, relating to the literature on the engagement of diasporas, ELECLAW can help reorient the focus beyond the analysis of positive cases to examining the full range of variation 
of non-resident citizens' voting rights across different levels of government, and how they relate with state-led diaspora policies (Gamlen et al. 2017). Furthermore, relating to research on non-citizen electoral rights or immigrant rights more generally, ELECLAW offers very fine-grained measures that leave the issue of aggregation across levels of election-which is especially thorny in the case of non-citizens-to the individual researcher rather than conflating them in a way that is of debatable validity (see e.g. Earnest 2015). Existing research shows the potential of this approach: Joachim Blatter and colleagues have crafted the Immigrant Inclusion Index (IMIX; Blatter et al. 2015b, 2017), which factors in an adapted and aggregated version of ELECLAW to measure one of the components to assess the electoral inclusiveness regarding non-citizen residents. Comparing twenty EU member states, they point to a substantial yet highly diverse "democratic deficit" with respect to immigrant inclusion.

As ELECLAW does not examine how non-resident citizens and non-citizen residents fall into those categories in the first place, another research avenue is to relate the inclusion of these groups to provisions for the acquisition and loss of citizenship. Indeed, ELECLAW can - and should - be combined with indicators for the acquisition and loss of citizenship such as CITLAW (Jeffers et al. 2017; Vink and Bauböck 2013), which is another resource offered by GLOBALCIT. These databases allow researchers to analyse and compare the inclusion into the demos as defined by two distinct but interactive pathways.

Last but not least, CANLAW provides a crucial resource to address the glaring lack of investigation into the variation of the inclusiveness of candidacy rights. The legal imbroglio in the aftermath of the referendum on independence in Catalonia on 1 October 2017 illustrates the importance of restrictions on the right to stand as candidate, such as those based on criminal offence. In the regional elections of early 2018, elected pro-independence candidates from the incumbent coalition-chiefly the former President Carles Puigdemont-were prevented from taking office. This was done, according to the Spanish government's Deputy Prime Minister at the time, using "every tool made available by the laws and the constitution to make sure that a fugitive cannot be sworn in and become the head of the regional government". ${ }^{12}$ Recent events in Brazil also offer a telling example. The decision of the Electoral Court to reject the candidacy of former President Luis Ignacio Lula, currently serving a 12-year prison sentence for corruption, in the October 2018 Presidential elections, arguably had considerable implications on electoral outcomes. ${ }^{13}$ In a different

\footnotetext{
12 Declaration by Soraya Saenz de Santamaria, deputy prime minister of the Spanish government, quoted in the article "Spanish government asks court to block Puigdemont's bid to lead Catalonia", Reuters, 28 January 2018.

13 These examples are illustrative of the importance and salience of formal electoral rules regulating the right to stand as candidate in contemporary democracies. To be sure, we do not claim that the decisions of the Spanish Constitutional Court, the Brazilian Electoral Commission, or the Australian High Court are either illegitimate or undemocratic. In fact, as we have tried to show, one of the core strengths of ELECLAW is that it is designed to minimise the need for normative judgement, by focusing on de jure regulations and measuring their relative inclusion towards a specific category of persons, while leaving the question of whether they are more or less democratic to the appreciation of users.
} 
yet no less contentious vein, the numerous resignations of Australian Members of Parliament due to their dual citizenship in May 2018 are a stark reminder of the fact that, just as voting rights, candidacy rights are non-universal and distributed unevenly across and within established democracies. We hope that ELECLAW can kick-start intensified efforts to explore these contested frontiers of citizenship and democracy in the twenty-first century.

Acknowledgements We are grateful to those who have helped develop and code the ELECLAW indicators and who have provided us with great support and incisive comments throughout the writing process. These include (in alphabetical order) Rainer Bauböck, Jelena Dzankic, Derek Hutcheson, Dejan Stjepanovic, and Maarten Vink. The ELECLAW indicators are the fruit of a large collaborative project which started in 2012. They have been developed by Jean-Thomas Arrighi, Rainer Bauböck, Samuel D. Schmid, and Lorenzo Piccoli in consultation with Maarten Vink and Derek Hutcheson and with the assistance of Dejan Stjepanovic and Jelena Dzankic. Fifty-one country experts were also involved in the data collection process and helped us navigate the subtleties of complexities of national electoral laws. We are immensely grateful to all of them for their help and support throughout the project.

Funding This research has been supported by the Global Governance Programme of the Robert Schuman Centre for Advanced Studies (European University Institute) and National Center of Competence in Research (NCCR) on the move funded by the Swiss National Science Foundation, and the European Research Council (ERC) under the European Union's Horizon 2020 research and innovation programme (Grant Agreement No. 716350).

OpenAccess This article is distributed under the terms of the Creative Commons Attribution 4.0 International License (http://creativecommons.org/licenses/by/4.0/), which permits unrestricted use, distribution, and reproduction in any medium, provided you give appropriate credit to the original author(s) and the source, provide a link to the Creative Commons license, and indicate if changes were made.

\section{References}

Arrhenius, G. 2018. The Democratic Boundary Problem Reconsidered. Ethics, Politics \& Society 1: 89-122.

Arrighi, J.T., and R. Bauböck. 2017. A Multilevel Puzzle: Migrants' Voting Rights in National and Local Elections. European Journal of Political Research 56(3): 619-639.

Arrighi, J.T., and D. Hutcheson. 2015. "Keeping Pandora's (Ballot) Box Half-Shut": A Comparative Inquiry Into the Institutional Limits of External Voting in EU Member States. Democratization 22(5): 884-905.

Arrighi, J.T., and J.M. Lafleur. 2017. Where and Why Can Expatriates Vote in Regional Elections? A Comparative Analysis of Regional Electoral Practices in Europe and North America. Journal of Ethnic and Migration Studies. https://doi.org/10.1080/1369183X.2017.1409164.

Bauböck, R. 2015. Morphing the Demos into the Right Shape. Democratization 22(5): 820-839.

Bauböck, R. 2017. Democratic Inclusion. Rainer Bauböck in Dialogue. Manchester: Manchester University Press.

Beckman, L. 2009. The Frontiers of Democracy: The Right to Vote and its Limits. Basingstoke: Palgrave Macmillan.

Beckman, L. 2014. The Accuracy of Electoral Regulations: The Case of the Right to Vote by People with Cognitive Impairments. Social Policy and Society 13(2): 221-233.

Blatter, J., A. Blättler, and S.D. Schmid. 2015a. What Happened/s To Inclusion? A Plea and Three Proposals for Closing the Gap Between Democratic Theory and Empirical Measurement of Democracies, IPSA Committee on Concepts and Methods Working Papers Series on Political Concepts, No. 64. 
Blatter, J., S.D. Schmid, and A. Blättler. 2015b. The Immigrant Inclusion Index (IMIX). A Tool for Assessing the Electoral Inclusiveness of Democracies with Respect to Immigrants, Working Paper Series Global Governance and Democracy, No. 8, 2nd edition. Department of Political Science, University of Lucerne.

Blatter, J., S.D. Schmid, and A.C. Blättler. 2017. Democratic Deficits in Europe: The Overlooked Exclusiveness of Nation-States and the Positive Role of the European Union. Journal of Common Market Studies 55(3): 449-467.

Bühlmann, M., W. Merkel, L. Müller, and B. Wessels. 2012. The Democracy Barometer. European Political Science 11(4): 519-536.

Collyer, M. 2014. Inside Out? Directly Elected 'Special Representation' of Emigrants in National Legislatures and the Role of Popular Sovereignty. Political Geography 41: 64-73.

Coppedge, M., J. Gerring, C.H. Knutsen, S.I. Lindberg, S.E. Skaaning, J. Teorell, J. Krusell, K.L. Marquardt, D. Pemstein, J. Pernes, N. Stepanova, E. Tzelgov, Y.T. Wang, J. Medzihorsky, and S. Wilson. 2018. V-Dem Codebook v8, Varieties of Democracy (V-Dem) Project.

Coppedge, D., A. Alvarez, and C. Maldonado. 2008. Two Persistent Dimensions of Democracy: Contestation and Inclusiveness. The Journal of Politics 70(3): 632-647.

Coppedge, M., J. Gerring, D. Altman, M. Bernhard, S. Fish, S. Fish, A. Hicken, M. Kroening, S. Lindberg, K. McMann, P. Paxton, H. Semetko, S. Skaaning, J. Staton, and J. Torell. 2011. Conceptualizing and Measuring Democracy: A New Approach. Perspectives on Politics 9(2): 247-267.

Dahl, R.A. 1971. Polyarchy: Participation and Opposition. New Haven: Yale University Press.

Dahl, R.A. 1989. Democracy and Its Critics. Yale: Yale University Press.

Dumbrava, C. 2014. Nationality, Citizenship and Ethno-Cultural Belonging. Basingstoke: Palgrave Macmillan.

Earnest, D.C. 2015. The Enfranchisement of Resident Aliens. Democratization 22(5): 861-883.

Easton, D. 1965. A Systems Analysis of Political Life. Chicago: University of Chicago Press.

Gamlen, A., M.E. Cummings, and P.M. Vaaler. 2017. Explaining the Rise of Diaspora Institutions. Journal of Ethnic and Migration Studies. https://doi.org/10.1080/1369183X.2017.1409163.

GLOBALCIT. 2019. ELECLAW Indicators. Version 5.1. San Domenico di Fiesole: European University Institute.

Goertz, G. 2006. Social Science Concepts: A User's Guide. Princeton: Princeton University Press.

Goodin, R.G. 2007. Enfranchising All Affected Interests, and Its Alternatives. Philosophy \& Public Affairs 35(1): 40-68.

Helbling, M., L. Bjerre, F. Römer, and M. Zobel. 2017. Measuring Immigration Policies: The IMPIC Database. European Political Science 16(1): 79-98.

Jeffers, K., I. Honohan, and R. Bauböck 2017. How to Measure the Purposes of Citizenship Laws: Explanatory Report for the CITLAW Indicators. Version 3.0. San Domenico di Fiesole: GLOBALCIT.

López-Guerra, C. 2014. Democracy and Disenfranchisement: The Morality of Electoral Exclusions. Oxford: Oxford University Press.

Merino, J.A. 2015. La reforma del artículo 75 de la LOREG como mecanismo de abstención inducida. Revista Jurídica 32(2015): 51-73.

Merkel, W., D. Bochsler, K. Bousbah, M. Bühlmann, H. Giebler, M. Hänni, L. Heyne, L. Müller, S. Ruth, and B. Wessels. 2016. Democracy Barometer. Codebook. Version 5. Aarau: Zentrum für Demokratie.

Munck, G.L., and J. Verkuilen. 2002. Conceptualizing and Measuring Democracy. Comparative Political Studies 35(1): 5-34.

Paxton, P., K.A. Bollen, D.M. Lee, and H. Kim. 2003. A Half-Century of Suffrage: New Data and a Comparative Analysis. Studies in Comparative International Development 38(1): 93-122.

Pedroza, L. 2015. The Democratic Potential of Enfranchising Resident Migrants. International Migration 53(3): 22-35.

Piccoli, L., S.D. Schmid, J.T. Arrighi, R. Bauböck, and J. Dzankic. 2017. Explanatory Note: Conditions for Electoral Rights 2017. San Domenico di Fiesole: GLOBALCIT.

Raad, R., J. Karlawish, and P.S. Appelbaum. 2009. The Capacity to Vote of Persons with Serious Mental Illness. Psychiatric Services 60(5): 624-628.

Rokkan, S. 1999. State Formation, Nation-Building, and Mass Politics in Europe. Oxford: Oxford University Press.

Schmid, S.D., J.T. Arrighi, and R. Bauböck. 2019. ELECLAW Indicators. Measuring Voting and Candidacy Rights of Resident Citizens, Non-Resident Citizens and Non-Citizen Residents. San Domenico di Fiesole: GLOBALCIT. 
Spiro, P.J. 2006. Perfecting Political Diaspora. NYU Law Review 81(1): 207-233.

Turcu, A. 2018. Reactive Limits to Diaspora Enfranchisement Policies: A Conceptual Categorization. Diaspora Studies 11(1): 1-24.

Vanhanen, T. 1990. The Process of Democratization: A Comparative Study of 147 States, 1980-1988. New York: Crane Russak.

Vink, M.P., and R. Bauböck. 2013. Citizenship Configurations: Analysing the Multiple Purposes of Citizenship Regimes in Europe. Comparative European Politics 11(5): 621-648.

Publisher's Note Springer Nature remains neutral with regard to jurisdictional claims in published maps and institutional affiliations.

Samuel D. Schmid is a doctoral researcher at the Department of Political and Social Sciences of the European University Institute (IT).

Lorenzo Piccoli is a research fellow at the Swiss Forum for Migration and Population Studies of the University of Neuchâtel $(\mathrm{CH})$ and a research associate at the Robert Schuman Centre for Advanced Studies of the European University Institute (IT).

Jean-Thomas Arrighi is a research fellow at the Swiss Forum for Migration and Population Studies of the University of Neuchâtel $(\mathrm{CH})$ and a research associate at the Robert Schuman Centre for Advanced Studies of the European University Institute (IT). 